\title{
MIR141 expression differentiates Hashimoto thyroiditis from PTC and benign thyrocytes in Irish archival thyroid tissues
}

\section{Emma R. Dorris*, Paul Smyth, John J. O'Leary and Orla Sheils}

Department of Histopathology, Sir Patrick Dun Research Laboratory, Trinity College Dublin, St. James' Hospital, Dublin, Ireland

\section{Edited by:}

Domenico Salvatore, Università degli

Studi di Napoli Federico II, Italy

Reviewed by:

Janete M. Cerutti, Universidade

Federal de São Paulo, Brazil

Ginesa M. Garcia Rostan, Valladolid

University, Spain

*Correspondence:

Emma R. Dorris, Department of Histopathology, Sir Patrick Dun

Research Laboratory, Trinity College

Dublin, St. James' Hospital,

Pathology Building, Dublin 8, Ireland.

e-mail: cantweer@tcd.ie
MicroRNAs (miRNAs) are small non-coding RNAs approximately 22 nucleotides in length that function as regulators of gene expression. Dysregulation of miRNAs has been associated with initiation and progression of oncogenesis in humans. Our group has previously described a unique miRNA expression signature, including the MIR200 family member MIR141, which can differentiate papillary thyroid cancer (PTC) cell lines from a control thyroid cell line. An investigation into the expression of MIR141 in a series of archival thyroid malignancies $[n=140$; classic PTC (cPTC), follicular variant PTC, follicular thyroid carcinoma, Hashimoto thyroiditis (HT), or control thyrocytes] was performed. Each cohort had a minimum of 20 validated samples surgically excised within the period 1980-2009. A subset of the HT and CPTC cohorts $(n=3)$ were also analyzed for expression of TGF $\beta R 1$, a key member of the TGF $\beta$ pathway and known target of MIR141. Laser capture microdissection was used to specifically dissect target cells from formalin-fixed paraffin-embedded archival tissue. Thyrocyte- and lymphocyte-specific markers (TSHR and LSP1, respectively), confirmed the integrity of cell populations in the HT cohort. RNA was extracted and quantitative RT-PCR was performed using comparative CT $(\Delta \Delta C T)$ analysis. Statistically significant $(p<0.05)$ differential expression profiles of MIR141 were found between tissue types. HT samples displayed significant downregulation of MIR141 compared to both CPTC and control thyrocytes. Furthermore, TGF $\beta R 1$ expression was detected in CPTC samples but not in HT thyrocytes. It is postulated that the downregulation of this miRNA is due, at least in part, to its involvement in regulating the TGF $\beta$ pathway. This pathway is exquisitely involved in T-cell autoimmunity and has previously been linked with HT. In conclusion, HT epithelium can be distinguished from CPTC epithelium and control epithelium based on the relative expression of MIR141.

Keywords: microRNA, thyroid, Hashimoto thyroiditis, papillary thyroid carcinoma

\section{INTRODUCTION}

Hashimoto thyroiditis (HT) is a chronic autoimmune disorder characterized by lymphocytic inflammation of the thyroid. This infiltration leads to apoptosis of thyrocytes and hypothyroidism. HT is the most common form of thyroiditis, with a strong prevalence for women over the age of 40 (Rosai, 2004). The triggers for this autoimmune response appear to be both humoral and cellular, with a complex etiology involving both genetic and environmental factors (Eschler et al., 2011). HT is associated with an increased incidence of papillary thyroid carcinoma (PTC). However, the relationship between HT and PTC remains controversial, with some arguing that the increased rate of screening in HT patients confounds the association between the two. However, RET/PTC chromosomal translocations, which were originally haled to be a unique biomarker of PTC, have been identified in greater than $95 \%$ of HT tissue samples, $84 \%$ of which had no evidence of malignancy (Sheils et al., 2000a). This evidence implies a shared molecular etiology between HT and PTC.
Carcinomas of the thyroid are the most common endocrine malignancy (Parkin et al., 2005, 2010). The most common thyroid carcinoma is the well-differentiated classic PTC (cPTC), which accounts for an estimated $80 \%$ of thyroid cancers. cPTC is typically easily recognized microscopically due to its characteristic papillae and optically clear nuclei. The papillae are frequently associated with the formation of follicles, the ratio of which vary greatly (Rosai, 2004). However, other subtypes of thyroid carcinoma can be more difficult to diagnose. The follicular variant of PTC (fvPTC) composes entirely or almost entirely of follicles. The diagnosis of fvPTC is primarily based on nuclear alterations associated with cPTC. Its invasiveness and incidence of nodal metastases also aid diagnoses. Follicular carcinoma of the thyroid (FTC) is usually a solitary neoplasm with a microscopic appearance varying from well-formed follicles to solid growth patterns (Rosai, 2004). Hence, accurate diagnosis of certain thyroid carcinomas, in particular the differential diagnoses of fvPTC and FTC may be problematic. Given the difficulties in differentiating between subtypes, and with a view to understanding the underlying pathology, 
thyroid cancer research is ongoing with a view to identifying more robust discriminators of disease and prognosis.

Profiling of microRNA (miRNA) dysregulation is a potential diagnostic tool (Braun and Hüttelmaier, 2011; Marini et al., 2011). Many miRNAs display exquisite tissue specificity that may aid in determining the tumor tissue-of-origin. It has been found that miRNA classification was more accurate than messenger RNA (mRNA) classification in determining tissue-of-origin in poorly differentiated tumors (Rosenfeld et al., 2008). An estimated 50\% of miRNAs are located at genomic regions linked to cancer. Nearly every type of tumor analyzed by miRNA profiling has shown significantly altered miRNA profiles compared to normal counterparts (Calin and Croce, 2006). Investigation into miRNA deregulation in PTC has identified aberrant miRNA expression profiles in PTCs compared to normal thyroid (He et al., 2005; Cahill et al., 2006; Pallante et al., 2006, 2010; Visone et al., 2007; Aherne et al., 2008). Cahill et al. (2006) identified a miRNA signature profile for a cPTC cell line that displays significant upregulaution of MIR141. In the present study, an investigation into the expression of MIR141 in a series of archival thyroid malignancies [cPTC, fvPTC, FTC, HT, or control (no evidence of disease or goiter tissues) tissues] was performed, with an aim to elucidating the expression MIR141 across subtypes of follicular thyroid neoplasia. Each cohort had a minimum of 20 validated samples surgically excised within the period 1980-2009. Multiple members of the TGF $\beta$ pathway, including transforming growth factor, beta receptor 1 (TGF $\beta$ R1), have been identified to be direct targets of MIR141 (Braun et al., 2010; Senanayake et al., 2012). This pathway is involved in signaling for the cytokine IL-2, which has a well documented association with HT (Weijl et al., 1993). Hence a subset of the cPTC and HT cohort were analyzed for TGF $\beta$ R1 gene expression.

\section{MATERIALS AND METHODS ETHICAL APPROVAL}

Full ethical approval was obtained for this study from the Joint St. James's Hospital/Adelaide and Meath National Children's Hospital Research Ethics Committee.

\section{TISSUE SAMPLE}

All samples chosen for this analysis were from different thyroid tissues excised between 1980 and 2009. All samples were derived from an Irish population to limit geographical variation. A cohort of 140 archival cases of formalin-fixed paraffin-embedded (FFPE) tissues was obtained from the archives at St. James's Hospital. The cohort comprised of 30 control (no evidence of malignancy or goiter) thyroid tissues, $30 \mathrm{cPTC}$ tissues, $28 \mathrm{fvPTC}$ tissues, 26 FTC tissues, and 26 HT tissues. All tissues had been assessed by a registered histopathologist and diagnoses confirmed according to the World Health Organisation classification guidelines.

\section{LASER CAPTURE MICRODISSECTION}

The FFPE tissue were cut using a HM325 rotary microtome (MSC, Dublin, Ireland) to $7 \mu \mathrm{m}$, mounted on uncharged slides and dried on a heating block to remove excess moisture. Slides were dewaxed and hematoxylin and eosin stained using the automated TissueTek DRS 2000 Autostainer (Sakura, CA, USA). Stained slides were mounted onto an Arcturus ${ }^{\mathrm{xt}}$ Microdissection instrument (MDS Analytical Technologies, CA, USA). LCM was used to capture (infrared $810 \mathrm{~nm}$ ) specific cell populations of interest onto CapSure ${ }^{\circledR}$ Macro LCM caps (MDS Analytical Technologies, CA, USA). To confirm the purity of thyrocytes captured from HT tissues, an area containing lymphocytic infiltrate from the same $7 \mu \mathrm{m}$ section of a representative subset of the HT tissues were also microdissected on to separate caps for real-time PCR comparison of thyrocyte-specific and lymphocyte-specific markers. Following microdissection the transfer film containing the captured cells was peeled off the CapSure ${ }^{\circledR}$ macro LCM cap and placed into sterile DNA LoBind tubes (Eppendorf AG, Hamburg, Germany) to maximize downstream recovery.

\section{NUCLEIC ACID EXTRACTION}

RNA was extracted using the RecoverAll ${ }^{\mathrm{TM}}$ total nucleic acid isolation kit optimized for FFPE samples (Applied Biosystems, CA, USA) following the supplied recommended protocol, with step B (deparaffinization) omitted as the sections had been deparaffinized during the H\&E staining protocol. The RNA quantity and quality were assessed using the NanoDrop ${ }^{\circledR}$ ND-1000 Spectrophotometer (Wilmington, USA).

\section{miRNA ANALYSIS}

Inventoried TaqMan ${ }^{\circledR}$ miRNA Assay (Applied Biosystems, CA, USA) were used to synthesize single stranded MIR141 and RNU6B (endogenous control) cDNA according to the supplied TaqMan ${ }^{\circledR}$ miRNA assays protocol. Reverse transcription was performed on a Gene Amp PCR System 9600 (Perkin Elmer, MA, USA) with thermal cycling parameters set as per the TaqMan ${ }^{\circledR}$ miRNA assays protocol.

Real-time PCR was performed according to TaqMan ${ }^{\circledR}$ miRNA assays protocol using MIR141-specific or RNU6B-specific inventoried real-time miRNA expression assays. The recommended protocol was adjusted such that the RT product was diluted $1 / 5$ for use in the assay, with the nuclease-free water adjusted accordingly. Real-time PCR was performed on an ABI Prism 7900HT Sequence Detection System (Applied Biosystems, CA, USA) according to supplied recommended protocol.

\section{mRNA ANALYSIS}

Reverse transcription was performed using the High Capacity cDNA Reverse Transcription Kit (Applied Biosystems, CA, USA) as per manufacturers protocol. Real-time PCR was performed using inventoried TaqMan ${ }^{\circledR}$ Gene Expression Assays according to manufacturer supplied protocol for thyroid stimulating hormone receptor (TSHR), lymphocyte-specific protein 1 (LSP1), TGF $\beta$ R1, and the endogenous control glyceraldehydes-3 phosphate dehydrogenase (GAPDH).

\section{DATA ANALYSIS}

MicroRNAs and gene expression was measured by relative quantitation (RQ). The comparative $C_{\mathrm{T}}\left(\Delta \Delta C_{\mathrm{T}}\right)$ method was used to calculate RQ of mRNA and miRNA expression, using GAPDH and RNU6B as the endogenous control for mRNA and miRNA expression, respectively. The same calibrator and threshold levels were used for all samples. Comparative studies were preformed 
on the data using the SDS2.1 software (Applied Biosystems, CA, USA). The study was then exported to the Microsoft ${ }^{\circledR}$ Office Excel ${ }^{\circledR}$ 2007 software (Microsoft Corporation, WA, USA), Minitab $16^{\circledR}$ (Minitab Inc., USA) and to STATA 8 software (StataCorp LP, TX, USA) for further analysis. Differentially expressed miRNA patterns across tissue types were identified by means of a one-way ANOVA. Statistical significance was set at $p<0.05$. The relative expression (RQ) of TSHR and LSP1 in LCM captured isolated thyrocytes was compared to that of parallel LCM captured populations containing lymphocytic infiltration. Statistical significance was set at $( \pm)$ twofold expression of thyrocyte-specific populations compared to parallel populations containing lymphocytic infiltrate.

\section{RESULTS \\ LASER CAPTURE MICRODISSECTION}

Of the 140 thyroid tissues in the cohort, laser capture microdissection of 24 tissues did not capture either sufficient quantity or sufficient quality of cells to extract detectable levels of RNA. Of the remaining 116 tissues, 111 (95.69\%) expressed the endogenous control, RNU6B, which was selected as the internal normalization control for miRNA quantitation. Of the 111 samples expressing the endogenous control, 104 samples also expressed MIR141. This cohort of samples expressing both RNU6B and MIR141 consisted of $20 \mathrm{cPTC}$ samples, $20 \mathrm{fvPTC}$ samples, 19 FTC samples, $21 \mathrm{HT}$ samples, and 24 control samples.

\section{CHARACTERIZATION OF MRNA FROM HT SAMPLES}

To confirm the purity of the LCM harvested cell populations (thyrocyte and lymphocyte), HT tissues were assayed for thyrocyteand lymphocyte-specific markers (TSHR and LSP1, respectively). mRNA extracted from thyrocytes harvested from HT tissues was compared to mRNA extracted from interspersed/adjacent areas of lymphocytic infiltrate captured separately but from the same $7 \mu \mathrm{m}$ sections. As expected, THSR was significantly upregulated in each isolated thyrocyte population compared to each parallel sample containing lymphocytic infiltrate. Conversely, LSP1 was detected in all of the harvested lymphocyte samples but was only detected in a single thyrocyte sample, albeit displaying significant downregulation compared to its paired lymphocyte extract (Figure 1).

\section{EXPRESSION OF MIR141 IN THYROID TISSUES}

A comparison of relative gene expression across the thyroid cohorts identifies an association between MIR141 expression and malignant thyroid phenotypes. Analysis of variance (oneway ANOVA) was performed on log transformed data between cohorts and identified statistical significance between populations $(p=0.01, F=5.40)$. Residual analysis on log transformed data confirmed normally distributed populations for each cohort $(p<0.005)$. Expression of MIR141 was significantly downregulated $(p<0.05)$ in HT samples compared to both control and cPTC samples (Figure 2). Analysis of variance also demonstrates that the follicular variant of PTC displays a statistically significant $(p<0.05)$ pattern of downregulation of MIR141 expression compared to both control and cPTC samples.

\section{TGFBR1 IS EXPRESSED IN cPTC BUT NOT IN HT THYROCYTES}

A subset of HT and $c$ PTC samples ( $n=3 /$ cohort) were assayed for the expression of TGF $\beta R 1$, a member of the TGF $\beta$ pathway and known target of MIR141 (Braun et al., 2010). Expression of TGF $\beta R 1$ was detected in the all of cPTC samples but not in HT thyrocytes. Paired HT lymphocytes $(n=3)$ were also assayed for TGF $\beta R 1$ and expression was detectable in these samples. As such, the cPTC subset $(n=3)$ were assayed for $L S P 1$ gene expression to confirm that the TGF $\beta R 1$ expression detected was not due to lymphocyte contamination. LSP1 gene expression was not detectable in the cPTC samples.

\section{DISCUSSION}

Inflammation and thyroid cancer are strongly linked. PTCs have a penchant to attract a florid of lymphocytic infiltrate. However, they can persist and metastasize in the presence of this infiltrate. Normal inflammation is self-limiting because the production of anti-inflammatory and pro-inflammatory cytokines is tightly regulated. During normal inflammation, blocking apoptosis provides time for DNA repair and the production of reactive oxygen species (ROS) fights against viral threat. However, the failure of mechanisms required for resolving the inflammatory response or the persistence of the initiating factors can result in chronic inflammation. ROS are mutagens. The blocking of apoptosis in cells that are gaining oncogenic mutations can lead to tumor progression. Thus chronic inflammation can act as both an initiator (DNA damage and growth signals) and as a promoter (blocking apoptosis and stimulating cell proliferation), which over time can induce oncogenesis.

Formalin-fixed paraffin-embedded tissue samples were used in this study. While FFPE preserves tissue for morphological analysis, the effect of formalin fixation on nucleic acids can hamper molecular analysis as nucleic acids become cross-linked during fixation. There are no standardized guidelines for processing FFPE tissues (Blow, 2007), and as such there can be great variation in the time between ligation of circulation and fixation. Nucleic acids suffer damage through fixation. The greater the time prior to fixation, the greater the exposure to nucleases and modifying enzymes, which are upregulated during ischemia. Nucleic acids are often irreversibly damaged and can become increasingly fragmented during prolonged storage (Burgemeister, 2011). Mature miRNAs, however, are approximately 22 nucleotides in length. Due to this small size they tend not to suffer from the fragmentation effect. Thus, FFPE tissues tend to yield miRNA more effectively than mRNA. It has previously been demonstrated that FFPE thyroid tissues are a suitable resource for miRNA expression analysis (Tetzlaff et al., 2007; Chen et al., 2008; Sheu et al., 2010). The method used for miRNA extraction in this study has previously been demonstrated to yield miRNA with expression levels that positively correlate with expression levels from snap frozen tissue (Li et al., 2007).

MicroRNAs have emerged as key regulators of the immune system, displaying unique expression profiles in cells of the adaptive and innate immune system (O'Connell et al., 2010). Aberrant expression of miRNAs has been documented in a range of diseases associated with the immune system, including cancer and autoimmunity (Calin et al., 2002; Xiao et al., 2008). MiRNA signatures that can distinguish thyroid malignancies in fine needle 


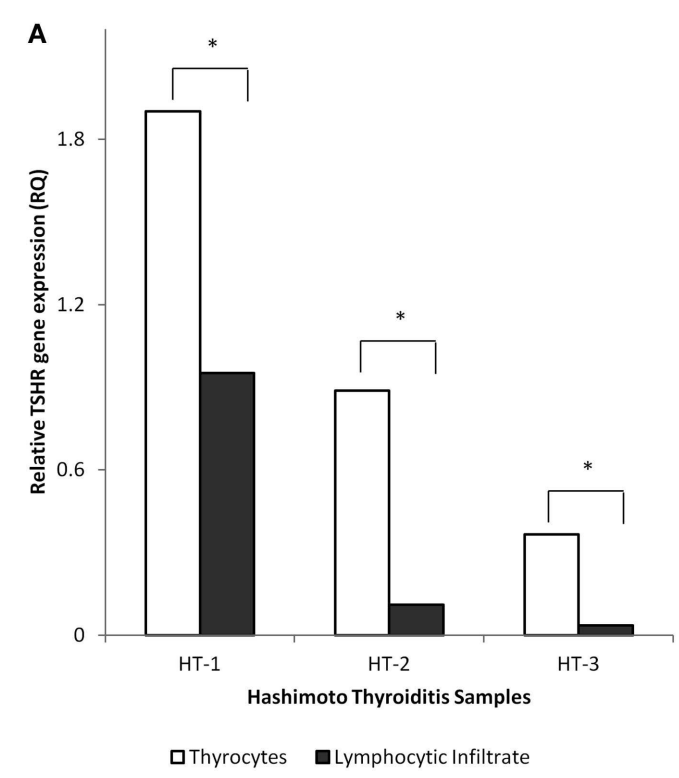

FIGURE 1 | Characterization of isolated thyrocytes from representative $\mathbf{H T}$ tissues. The thyrocyte population was captured using LCM. An adjacent/interspersed area from the same $7 \mu \mathrm{m}$ section containing lymphocytic infiltrate was captured on a separate cap for comparison of gene expression. Relative gene expression of TSHR (A) and $L S P 1$ (B) was measured between groups. The isolated thyrocytes had significantly upregulated levels of TSHR compared to

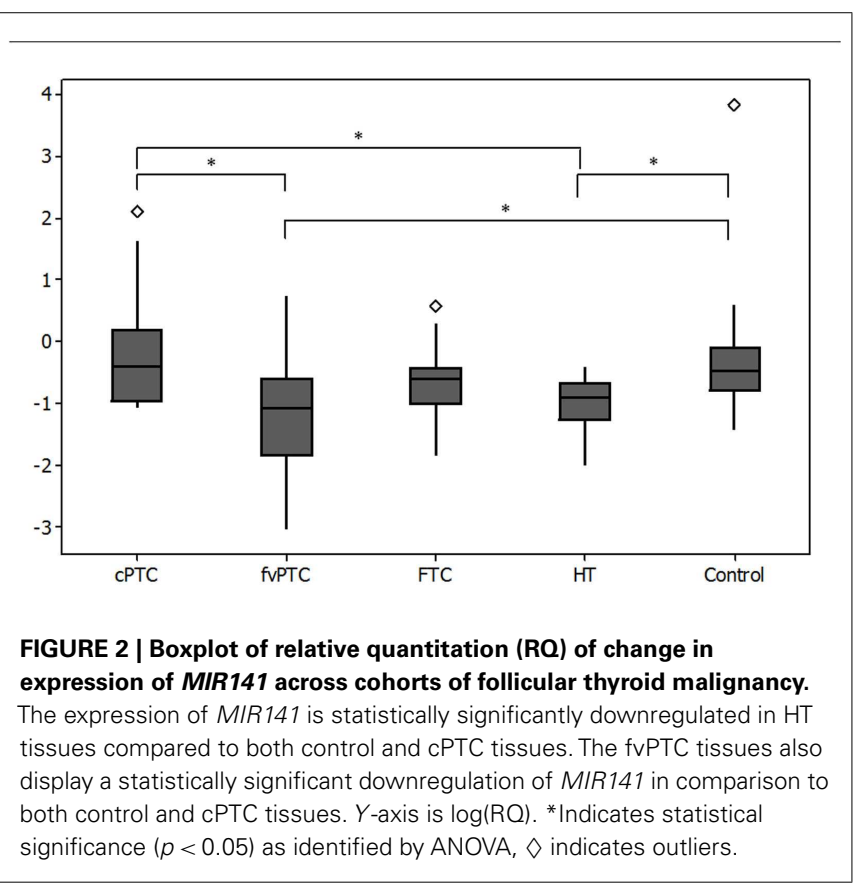

aspiration, FFPE, and fresh surgical samples have been identified (He et al., 2005; Pallante et al., 2006; Tetzlaff et al., 2007; Chen et al., 2008; Nikiforova et al., 2008; Sheu et al., 2010; Shen et al., 2012; Vriens et al., 2012). It has been demonstrated that MIR141 is upregulated in a cell line model of ret/PTC-1 associated PTC

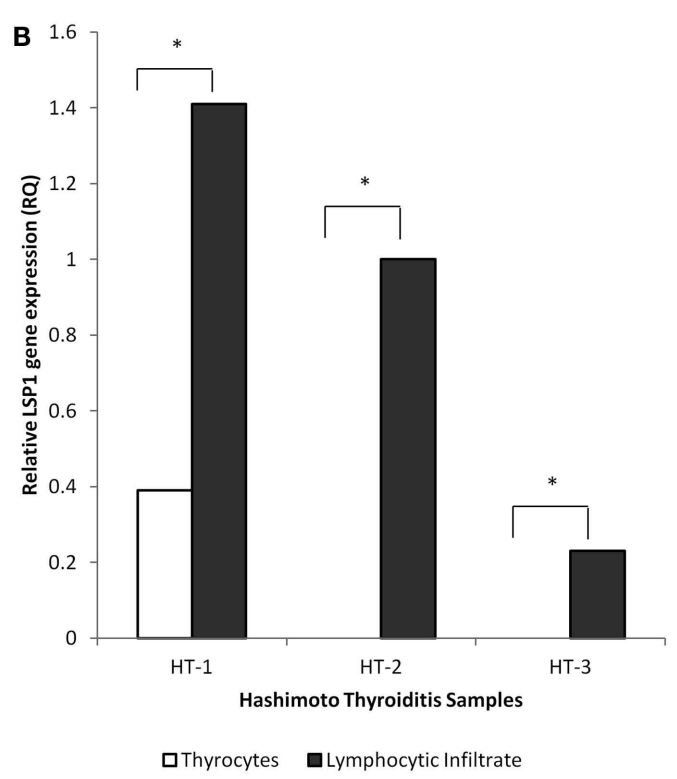

populations containing lymphocytic infiltrate. LSP1 was only detected in 1 sample (HT-1) of isolated thyrocytes and was significantly downregulated compared to the parallel lymphocyte sample. * Indicates statistical significance of \pm twofold difference in relative gene expression of thyrocyte-specific populations compared to parallel populations containing lymphocytic infiltrate. $Y$-axis is fold change in gene expression (RQ).

(Cahill et al., 2006). In the current study, we investigated if the pattern of MIR141 expression would translate to clinical specimens. In fact, the pattern of upregulated MIR141was not observed in the study sample. This may be due to (a) variation between in vitro and in vivo expression or (b) the low rate of ret/PTC variants in the samples analyzed (Table $\mathbf{1}$ ).

In this study a significantly decreased expression of MIR141 was identified in thyrocytes isolated from HT tissues compared to both control and cPTC samples. This is of particular interest as it has been postulated that HT represents a circumstance in which thyrocytes are in a state between normal and neoplastic (Sheils et al., 2000b). Histologically, HT can present with the occurrence of nuclear clearing and overlapping cells associated with PTC, but without evidence of malignancy (Rosai, 2004). On a molecular level, previous studies (Wirtschafter et al., 1997; Sheils et al., 2000a; Rhoden et al., 2006) detected that up to $95 \%$ of HT samples displayed evidence of ret/PTC-1 activation, including HT samples that had no evidence of malignancy. The ret/PTC chromosomal rearrangement was previously considered to be a hallmark of PTC. However, evidence of their presence in HT samples indicates a more complex role of this genetic alteration. Furthermore; the occurrence of non-specific lymphocytic infiltrate in PTC tissues has been positively associated with the presence of RET/PTC-1 expression (Sheils et al., 2000b). This has lead to the postulation that antigenic alterations induced by genetic alterations such as the activation of c-ret are responsible for eliciting an immune response within the thyroid tissue. In HT, it is feasible that the presence of genetic alterations such as c-ret elicit an immune response to curtail the development of PTC. A subset of patients may be 
Table 1 | Mutational status of RET/PTC-1 and RET/PTC-3 for PTC samples expressing MIR141.

\begin{tabular}{|c|c|c|c|c|c|}
\hline PTC variant & Year of biopsy & RET/PTC mutation & PTC variant & Year of biopsy & RET/PTC mutation \\
\hline Classic & 1980 & Unknown & Follicular variant & 1986 & Negative \\
\hline Classic & 1985 & Unknown & Follicular variant & 1987 & Unknown \\
\hline Classic & 1994 & RET/PTC-1 & Follicular variant & 1991 & Negative \\
\hline Classic & 1998 & Negative & Follicular variant & 1991 & Negative \\
\hline Classic & 2002 & Negative & Follicular variant & 1992 & Unknown \\
\hline Classic & 2002 & Negative & Follicular variant & 1992 & Negative \\
\hline Classic & 2003 & Negative & Follicular variant & 1993 & RET/PTC-3 \\
\hline Classic & 2004 & Negative & Follicular variant & 1996 & Unknown \\
\hline Classic & 2004 & Negative & Follicular variant & 2001 & Negative \\
\hline Classic & 2005 & Negative & Follicular variant & 2004 & Negative \\
\hline Classic & 2005 & Negative & Follicular variant & 2004 & Negative \\
\hline Classic & 2005 & Negative & Follicular variant & 2005 & Negative \\
\hline Classic & 2005 & Negative & Follicular variant & 2005 & Negative \\
\hline
\end{tabular}

successfully in this regard but with background damage of autoimmune destruction of thyroid tissue. However, the relationship between HT and PTC remains a highly controversial issue.

MIR141 has been confirmed to directly target a number of genes. Multiple members of the TGF $\beta$ pathway have been identified to be direct targets of MIR141 (Braun et al., 2010; Senanayake et al., 2012). Braun et al. (2010) demonstrated direct targeting of TGF $\beta$ R 1 and SMAD family member 2 (SMAD 2). Both TGF $\beta 1$ and SMAD2 are negatively regulated by MIR141. These key members of the TGF $\beta$ signaling pathway act to signal for interleukin-2 (IL-2), a cytokine involved in T-cell proliferation. T-cells play a crucial role in the development of HT as they secrete inflammatory cytokines in reaction to auto-antigens; primarily TSHR and thyroid peroxidase (TPO). IL-2 is essential for T-cell determination of self from non-self. IL-2R $\beta /$ IL-2 knock-out mice developed a marked increase in T-cell mediated autoimmunity and deregulated T-cell proliferation. Furthermore, IL-2 is used as treatment for certain cancers, which is documented to result in an increased risk of HT (Weijl et al., 1993). Thus, the association of MIR141 with the regulation of this pathway may be reflected in its downregulation in HT epithelium. The relative expression of TGF $\beta$ R1 was assayed in a subset of samples $(n=3)$ in this study. TGF $R 1$ was found to be expressed in CPTC samples but not in isolated HT thyrocytes. MIR141 expression is upregulated in these CPTC samples compared to the isolated HT thyrocyte samples. This initial data supports the argument for further investigation into the association of MIR141, the TGF $\beta$ signaling pathway and HT.

Thyroid carcinomas frequently present with multiple phenotypic tumor-foci within a single thyroid gland. Direct experimental analysis of these tissues will therefore reflect the predominant cell type within the tissue which may not be the cell of interest nor be biologically relevant to the neoplasm under investigation. MiRNA profiles have been found to distinguish tumor types within a single thyroid biopsy (Aherne et al., 2008). This highlights the requirement to extract a pure population of the specific tumor cells in order to identify and accurately define the molecular processes in pathogenic lesions. LCM provides a non-damaging microdissection process which allows isolation of pure populations while preserving the integrity of the captured material (Liu, 2010). In this study, LCM was utilized to specifically select the cell-types of interest and therefore reduce the confounding factors associated with whole section analysis. This enforces the accuracy of the associations identified between MIR141 and malignant thyroid phenotypes.

In conclusion, HT epithelium can be distinguished from neoplastic follicular thyroid epithelium isolated from cPTC and control epithelium based on the relative expression of MIR141. It is postulated that the downregulation of this miRNA may be due, at least in part, to its involvement in regulating the TGF $\beta$ signaling pathway. The MIR200 family, including MIR141, have been demonstrated to directly regulate members of this pathway as part of a regulatory feedback loop. The preliminary data presented here in combination with data from the literature (Braun et al., 2010; Senanayake et al., 2012) leads this postulation to warrant further investigation. The TGF $\beta$ pathway is exquisitely involved in T-cell autoimmunity and has been linked with HT for some time, as treatment of cancer patients with IL-2, a downstream target of the pathway, resulted in increased incidence of HT (Weijl et al., 1993). Further investigation of MIR141 and its regulatory networks may aid in elucidating the molecular mechanisms that result in the fundamental physiological differences between these malignant thyroid phenotypes.

\section{ACKNOWLEDGMENTS}

Emma R. Dorris is funded by the Health Research Board of Ireland's PhD Scholars Programme. 


\section{REFERENCES}

Aherne, S. T., Smyth, P. C., Flavin, R. J., Russell, S. M., Denning, K. M., Li, J. H., Guenther, S. M., O'Leary, J. J., and Sheils, O. M. (2008). Geographical mapping of a multifocal thyroid tumour using genetic alteration analysis and miRNA profiling. Mol. Cancer 7, 89.

Blow, N. (2007). Tissue preparation: tissue issues. Nature 448, 959-963.

Braun, J., Hoang-Vu, C., Dralle, H., and Hüttelmaier, S. (2010). Downregulation of microRNAs directs the EMT and invasive potential of anaplastic thyroid carcinomas. Oncogene 29, 4237-4244.

Braun, J., and Hüttelmaier, S. (2011). Pathogenic mechanisms of deregulated microRNA expression in thyroid carcinomas of follicular origin. Thyroid Res. 4(Suppl. 1), S1.

Burgemeister, R. (2011). Nucleic acids extraction from laser microdissected FFPE tissue sections. Methods Mol. Biol. 724, 117-129.

Cahill, S., Smyth, P., Finn, S. P., Denning, K., Flavin, R., O'Regan, E. M., Li, J., Potratz, A., Guenther, S. M., Henfrey, R., O'Leary, J. J., and Sheils, O. (2006). Effect of ret/PTC 1 rearrangement on transcription and post-transcriptional regulation in a papillary thyroid carcinoma model. Mol. Cancer 5, 70.

Calin, G. A., and Croce, C. M. (2006). MicroRNA signatures in human cancers. Nat. Rev. Cancer 6, 857-866.

Calin, G. A., Dumitru, C. D., Shimizu, M., Bichi, R., Zupo, S., Noch, E., Aldler, H., Rattan, S., Keating, M., Rai, K., Rassent, L., Kipps, T., Negrini, M., Bullrich, F., and Croce, C. M. (2002). Frequent deletions and down-regulation of micro-RNA genes miR15 and miR16 at 13q14 in chronic lymphocytic leukemia. Proc. Natl. Acad. Sci. U.S.A. 99, 15524-15529.

Chen, Y. T., Kitabayashi, N., Zhou, X. K., Fahey, T. J., and Scognamiglio, T. (2008). MicroRNA analysis as a potential diagnostic tool for papillary thyroid carcinoma. Mod. Pathol 21, 1139-1146.

Eschler, D. C., Hasham, A., and Tomer, Y. (2011). Cutting edge: the etiology of autoimmune thyroid diseases. Clin. Rev. Allergy Immunol. 13, 33-39.

He, H., Jazdzewski, K., Li, W., Liyanarachchi, S., Nagy, R., Volinia, S., Calin, G. A., Liu, C. G., Franssila, K., Suster, S., Kloos, R. T., Croce, C. M., and de la Chapelle, A. (2005). The role of microRNA genes in papillary thyroid carcinoma. Proc. Natl. Acad. Sci. U.S.A. 102, 19075-19080.

Li, J., Smyth, P., Flavin, R., Cahill, S., Denning, K., Aherne, S., Guenther,
S. M., O'Leary, J. J., and Sheils, O. (2007). Comparison of miRNA expression patterns using total RNA extracted from matched samples of formalin-fixed paraffin embedded FFPE cells and snap frozen cells. BMC. Biotechnol. 7, 36. doi:10.1186/1472-6750-7-36

Liu, A. (2010). Laser capture microdissection in the tissue biorepository. $J$. Biomol. Tech. 21, 120-125.

Marini, F., Luzi, E., and Brandi, M. L. (2011). MicroRNA role in thyroid cancer development. J. Thyroid Res. doi: 10.4061/2011/407123

Nikiforova, M. N., Tseng, G. C., Steward, D., Diorio, D., and Nikiforov, Y. E. (2008). MicroRNA expression profiling of thyroid tumors: biological significance and diagnostic utility. J. Clin. Endocrinol. Metab. 93, 1600-1608.

O’Connell, R. M., Rao, D. S., Chaudhuri, A. A., and Baltimore, D. (2010). Physiological and pathological roles for microRNAs in the immune system. Nat. Rev. Immunol. 10, 111-122.

Pallante, P., Visone, R., Croce, C. M., and Fusco, A. (2010). Deregulation of microRNA expression in follicularcell-derived human thyroid carcinomas. Endocr. Relat. Cancer 17, F91-F104.

Pallante, P., Visone, R., Ferracin, M., Ferraro, A., Berlingieri, M. T., Troncone, G., Chiappetta, G., Liu, C. G., Santoro, M., Negrini, M., Croce, C. M., and Fusco, A. (2006). MicroRNA deregulation in human thyroid papillary carcinomas. Endocr. Relat. Cancer 13, 497-508.

Parkin, D. M., Bray, F., Ferlay, J., and Pisani, P. (2005). Global cancer statistics, 2002. CA Cancer J. Clin. 55, 74-108.

Parkin, D. M., Ferlay, J., Curado, M. P., Bray, F., Edwards, B., Shin, H. R., and Forman, D. (2010). Fifty years of cancer incidence: CI5 I-IX. Int. J. Cancer 127, 2918-2927.

Rhoden, K. J., Unger, K., Salvatore, G., Yilmaz, Y., Vovk, V., Chiappetta, G., Qumsiyeh, M. B., Rothstein, J. L., Fusco, A., Santoro, M., Zitzelsberger, H., and Tallini, G. (2006). RET/Papillary thyroid cancer rearrangement in nonneoplastic thyrocytes: follicular cells of Hashimoto's thyroiditis share lowlevel recombination events with a subset of papillary carcinoma. J. Clin. Endocrinol. Metab. 91, 2414-2423.

Rosai, J. (ed.) (2004). “Thyroid Gland," in Rosai and Ackerman's Surgical Pathology, 9th Edn. (St. Louis: Mosby), 1, 515-595.
Rosenfeld, N., Aharonov, R., Meiri, E., Rosenwald, S., Spector, Y., Zepeniuk, M., Benjamin, H., Shabes, N., Tabak, S., Levy, A., Lebanony, D., Goren, Y., Silberschein, E., Targan, N., Ben-Ari, A., Gilad, S., SionVardy, N., Tobar, A., Feinmesser, M., Kharenko, O., Nativ, O., Nass, D., Perelman, M., Yosepovich, A., Shalmon, B., Polak-Charcon, S., Fridman, E., Avniel, A., Bentwich, I., Bentwich, Z., Cohen, D., Chajut, A., and Barshack, I. (2008). MicroRNAs accurately identify cancer tissue origin. Nat. Biotechnol. 26, 462-469.

Senanayake, U., Das, S., Vesely, P., Alzoughbi, W., Fröhlich, L. F., Chowdhury, P., Leuschner, I., Hoefler, G., and Guertl, B. (2012). miR192, miR-194, miR-215, miR-200c and $\mathrm{miR}-141$ are downregulated and their common target ACVR2B is strongly expressed in renal childhood neoplasms. Carcinogenesis 33, 1014-1021.

Sheils, O. M., O'eary, J. J., Uhlmann, V., Lättich, K., and Sweeney, E. C. (2000a). ret/PTC-1 Activation in Hashimoto thyroiditis. Int. J. Surg. Pathol. 8, 185-189.

Sheils, O. M., O'Leary, J. J., and Sweeney, E. C. (2000b). Assessment of ret/PTC-1 rearrangements in neoplastic thyroid tissue using TaqMan RT-PCR. J. Pathol. 192, 32-36.

Shen, R., Liyanarachchi, S., Li, W., Wakely, P. E., Saji, M., Huang, J., Nagy, R., Farrell, T., Ringel, M. D., de la Chapelle, A., Kloos, R. T., and He, H. (2012). MicroRNA signature in thyroid fine needle aspiration cytology applied to "atypia of undetermined significance" cases. Thyroid 22, 9-16.

Sheu, S. Y., Grabellus, F., Schwertheim, S., Worm, K., Broecker-Preuss, M., and Schmid, K. W. (2010). Differential miRNA expression profiles in variants of papillary thyroid carcinoma and encapsulated follicular thyroid tumours. Br. J. Cancer 102, 376-382.

Tetzlaff, M. T., Liu, A., Xu, X., Master, S. R., Baldwin, D. A., Tobias, J. W., Livolsi, V. A., and Baloch, Z. W. (2007). Differential expression of miRNAs in papillary thyroid carcinoma compared to multinodular goiter using formalin fixed paraffin embedded tissues. Endocr. Pathol. 18, 163-173.

Visone, R., Pallante, P., Vecchione, A., Cirombella, R., Ferracin, M., Ferraro, A., Volinia, S., Coluzzi, S., Leone, V., Borbone, E., Liu, C. G., Petrocca, F., Troncone, G., Calin, G. A., Scarpa, A., Colato, C., Tallini, G.,
Santoro, M., Croce, C. M., and Fusco, A. (2007). Specific microRNAs are downregulated in human thyroid anaplastic carcinomas. Oncogene 26, 7590-7595.

Vriens, M. R., Weng, J., Suh, I., Huynh, N., Guerrero, M. A., Shen, W. T., Duh, Q. Y., Clark, O. H., and Kebebew, E. (2012). MicroRNA expression profiling is a potential diagnostic tool for thyroid cancer. Cancer 118, 3426-3432.

Weijl, N. I., Van der Harst, D., Brand, A., Kooy, Y., Van Luxemburg, S., Schroder, J., Lentjes, E., Van Rood, J. J., Cleton, F. J., and Osanto, S. (1993). Hypothyroidism during immunotherapy with interleukin-2 is associated with antithyroid antibodies and response to treatment. J. Clin. Oncol. 11, 1376-1383.

Wirtschafter, A., Schmidt, R., Rosen, D., Kundu, N., Santoro, M., Fusco, A., Multhaupt, H., Atkins, J. P., Rosen, M. R., Keane, W. M., and Rothstein, J. L. (1997). Expression of the RET/PTC fusion gene as a marker for papillary carcinoma in Hashimoto's thyroiditis. Laryngoscope 107, 95-100.

Xiao, C., Srinivasan, L., Calado, D. P., Patterson, H. C., Zhang, B., Wang, J., Henderson, J. M., Kutok, J. L., and Rajewsky, K. (2008). Lymphoproliferative disease and autoimmunity in mice with increased miR-1792 expression in lymphocytes. Nat. Immunol. 9, 405-414.

Conflict of Interest Statement: The authors declare that the research was conducted in the absence of any commercial or financial relationships that could be construed as a potential conflict of interest.

Received: 02 April 2012; accepted: 04 August 2012; published online: 03 September 2012.

Citation: Dorris ER, Smyth P, O'Leary JJ and Sheils $O$ (2012) MIR141 expression differentiates Hashimoto thyroiditis from PTC and benign thyrocytes in Irish archival thyroid tissues. Front. Endocrin. 3:102. doi: 10.3389/fendo.2012.00102

This article was submitted to Frontiers in Thyroid Endocrinology, a specialty of Frontiers in Endocrinology.

Copyright (c) 2012 Dorris, Smyth, O'Leary and Sheils. This is an openaccess article distributed under the terms of the Creative Commons Attribution License, which permits use, distribution and reproduction in other forums, provided the original authors and source are credited and subject to any copyright notices concerning any third-party graphics etc. 